\title{
Reply to the editor
}

\author{
Hideki Hino $^{1}\left[\right.$ Tadashi Matsuura $^{1}$
}

Received: 7 September 2019 / Accepted: 16 September 2019 / Published online: 27 September 2019

(c) Japanese Society of Anesthesiologists 2019

Keywords Propofol $\cdot$ Thiopental $\cdot$ ClearSight $₫$ system

To the Editor:

We thank the readers for valuable comments on our publication [1]. It is conceivable that hypertension, diabetes, and fasting time could affect the results of our randomized study.

However, the presence of hypertension and diabetes was shown in Supplementary Table 1 and there was no difference between the two groups in each age group. These results were similar to the prevalence from surveys in Japan [2, 3]. Due to the nature of prospective randomized studies, patients' backgrounds in study groups should not be different. Therefore, as long as there is no evidence that propofol is more potent in patients with hypertension or diabetes compared with thiopental, the effects of them on the results would not be crucial. Moreover, because diabetic patients with poorly controlled glycemia, who could have severe autonomic neuropathy, are usually classified as ASA-PS 3 at best, such patients were excluded from the study.

In our institution, fasting time before surgery is $2 \mathrm{~h}$ for clear liquids and $6 \mathrm{~h}$ for solids, which has been recommended by ASA guidelines. Although the final intakes before surgery were not recorded, it is thought that there was no difference between the two groups as well as for the numbers of patients with hypertension or diabetes.

This reply refers to the article available at https://doi.org/10.1007/ s00540-019-02686-6.

Electronic supplementary material The online version of this article (https://doi.org/10.1007/s00540-019-02687-5) contains supplementary material, which is available to authorized users.

Hideki Hino

m1165192@yahoo.co.jp

1 Department of Anesthesiology, Osaka City University Graduate School of Medicine, 1-5-7 Asahimachi, Abeno-ku, Osaka 545-8586, Japan
Funding No funding was received.

\section{Compliance with ethical standards}

Conflict of interest The authors declare that they have no conflict of interest.

\section{References}

1. Hino H, Matsuura T, Kihara Y, Tsujikawa S, Mori T, Nishikawa $\mathrm{K}$. Comparison between hemodynamic effects of propofol and thiopental during general anesthesia induction with remifentanil infusion: a double-blind, age-stratified, randomized study. J Anesth. 2019;33:509-15.

2. Miura K, Nagai M, Ohkubo T. Epidemiology of hypertension in Japan: where are we now? Circ J. 2013;77:2226-31.

3. Mukai N, Hata J, Hirakawa Y, Ohara T, Yoshida D, Nakamura U, Kitazono T, Ninomiya T. Trends in the prevalence of type 2 diabetes and prediabetes in a Japanese community, 1988-2012: the Hisayama Study. Diabetol Int. 2019;10:198-205.

Publisher's Note Springer Nature remains neutral with regard to jurisdictional claims in published maps and institutional affiliations. 